\section{Case Reports in Nephrology and Dialysis}

Case Rep Nephrol Dial 2020;10:104-108

\begin{tabular}{l|l}
\hline DOI: $10.1159 / 000510143$ & (c) 2020 The Author(s)
\end{tabular}

Published online: October 5, 2020

Published by S. Karger AG, Basel www.karger.com/cnd

This article is licensed under the Creative Commons Attribution-NonCommercial 4.0 International License (CC BY-NC) (http://www.karger.com/Services/OpenAccessLicense). Usage and distribution for commercial purposes requires written permission.

\title{
Limited Treatment Options in Primary Hyperoxaluria with Renal Failure
}

\author{
Kyle Geiger ${ }^{a}$ Henry Mroch ${ }^{a, b}$ \\ aElson S. Floyd College of Medicine, Washington State University, Spokane, WA, USA;

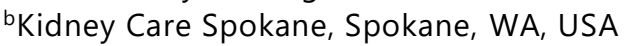

\section{Keywords}

Primary hyperoxaluria $\cdot$ Renal biopsy $\cdot$ Chronic hemodialysis $\cdot$ Chronic renal failure $\cdot$ Genetic diseases

\begin{abstract}
Primary hyperoxaluria $(\mathrm{PH})$ is a rare autosomal recessive metabolic disorder where serum oxalate levels rise due to overproduction. The kidney tubule is a main target for oxalate deposition, resulting in damage to the organ. Kidney failure is rare in these patients. We present a 67-year-old female with hemodialysis-dependent end-stage renal disease likely due to $\mathrm{PH}$ type 2 or 3 . With extremely high levels of serum oxalate $(60.4 \mu \mathrm{mol} / \mathrm{L})$, this patient had minimal treatment options for her rare disease. This report details a unique presentation of a rare disease where kidney biopsy was instrumental.

(c) 2020 The Author(s)

Published by S. Karger AG, Basel
\end{abstract}

\section{Introduction}

Primary hyperoxaluria (PH) types 1, 2, and 3 are autosomal recessive disorders with errors in the metabolism of glyoxylate and oxalate [1]. In these disorders, serum oxalate levels rise due to overproduction. The kidney tubule is a main target for oxalate deposition, resulting in damage to the organ. The incidence of $\mathrm{PH}$ is estimated to be 1 in 58,000. Type 1 is the most common form, accounting for approximately $80 \%$ of cases. Types 2 and 3 each account for 


\section{Case Reports in Nephrology and Dialysis}

Geiger and Mroch: Limited Treatment Options in Primary Hyperoxaluria with Renal Failure

about $10 \%$ of cases [2]. Kidney failure is rare in patients with PH. By comparison, there is increased incidence in secondary hyperoxaluria resulting in advanced chronic kidney injury in the setting of gastric bypass surgery and enteric disorders such as inflammatory bowel disease and short bowel syndrome. Other reports of nonenteric secondary hyperoxaluria are seen in instances of excessive vitamin $\mathrm{C}$ ingestion. We present a 67-year-old female with endstage renal failure likely due to PH type 2 or 3.

\section{Case Presentation}

The patient was a 67-year-old female with hemodialysis-dependent end-stage renal disease. The etiology of her renal failure was unclear with no obvious risk factors. She initially presented with a 1-month history of nausea, vomiting, and a 20-pound weight loss. There was no past history of enteric disorders, malabsorption, or use of vitamin supplements. Her serum creatinine was $4.91 \mathrm{mg} / \mathrm{dl}$ with a BUN of 81. A kidney biopsy showed oxalate nephropathy (Fig. 1) with tubular atrophy and interstitial fibrosis (Fig. 2). The patient underwent genetic testing for AGXT, the mutation seen in PH type 1 [1], and was negative. She is currently on a low-oxalate diet and taking pyridoxine (vitamin B6). However, her plasma oxalate levels remain elevated at $60.4 \mu \mathrm{mol} / \mathrm{L}$ (normal range 1.3-3.1 $\mu \mathrm{mol} / \mathrm{L}$ ) [3]. Despite excellent dialysis adequacy and treatment adherence, her interdisciplinary team concluded her oxalate levels were so high that a kidney transplantation would be likely to have reduced survival.

\section{Discussion}

In $\mathrm{PH}$, specific deficiencies of hepatic enzymes cause oxalate overproduction. Oxalate deposits in the kidney tubules can lead to nephropathy and possible kidney failure. Genetic studies aid in the diagnosis of $\mathrm{PH}$, typically showing mutations in the target genes AGXT, GPHPR, and HOGA1 for types 1, 2, and 3, respectively. Negative testing for PH type 1 led us to believe our patient has PH type 2 or 3 . Diagnosis of PH type 1 would make the patient a potential candidate for combined liver and kidney transplantation. However, treatment for those with end-stage renal disease for PH type 2 and 3 is unclear. Renal transplantation was evaluated although outcomes are poor [4]. Because of this, further genetic testing for types 2 and 3 was deferred because it would not impact clinical decision-making. Her care team is exploring the option of an expanded donor kidney transplantation and this is currently under evaluation. There is a paucity of information in the literature to guide our clinical decision-making in this context. The role for liver transplantation in addition to kidney transplantation remains ambiguous, however it is thought this may be curative because GRHPR enzymatic activity in the liver is high [5], and recent case reports are promising [6]. This case presents a unique diagnostic challenge where kidney biopsy was instrumental.

\section{Statement of Ethics}

All treatments and examinations followed the guidance of the Declaration of Helsinki. The subject gave her written informed consent to publish their case (including publication of images). 


\section{Conflict of Interest Statement}

The authors have no conflicts of interest to declare.

\section{Funding Sources}

This project was not supported by any grant or funding agencies.

\section{Author Contributions}

K. Geiger contributed to acquisition of data and writing of the manuscript. H. Mroch provided supervision and mentorship. Both authors approved the final manuscript.

\section{References}

1 Bouzidi H, Majdoub A, Daudon M, Najjar MF. Primary hyperoxaluria: a review. Nephrol Ther. 2016 Nov 12(6):431-6. French

2 Genetics Home Reference. Primary hyperoxaluria. https://ghr.nlm.nih.gov/condition/primaryhyperoxaluria [accessed March 11, 2020].

3 Kasidas GP, Rose GA. Measurement of plasma oxalate in healthy subjects and in patients with chronic renal failure using immobilised oxalate oxidase. Clin Chim Acta. 1986 Jan;154(1):49-58.

4 Cai R, Lin M, Chen Z, Lai Y, Huang X, Zhao G, et al. Primary hyperoxaluria diagnosed after kidney transplantation failure: lesson from 3 case reports and literature review. BMC Nephrol. 2019 Jun;20(1):224.

5 Giafi CF, Rumsby G. Kinetic analysis and tissue distribution of human D-glycerate dehydrogenase/glyoxylate reductase and its relevance to the diagnosis of primary hyperoxaluria type 2. Ann Clin Biochem. 1998 Jan; 35(Pt 1):104-9.

6 Dhondup T, Lorenz EC, Milliner DS, Lieske JC. Combined Liver-Kidney Transplantation for Primary Hyperoxaluria Type 2: A Case Report. Am J Transplant. 2018 Jan;18(1):253-7. 
Case Reports in Nephrology and Dialysis

\begin{tabular}{l|l}
\hline Case Rep Nephrol Dial 2020;10:104-108 \\
\hline DOI: 10.1159/000510143 & $\begin{array}{l}\text { (c) 2020 The Author(s). Published by S. Karger AG, Basel } \\
\text { www.karger.com/cnd }\end{array}$ \\
\hline Geiger and Mroch: Limited Treatment Options in Primary Hyperoxaluria with Renal
\end{tabular}

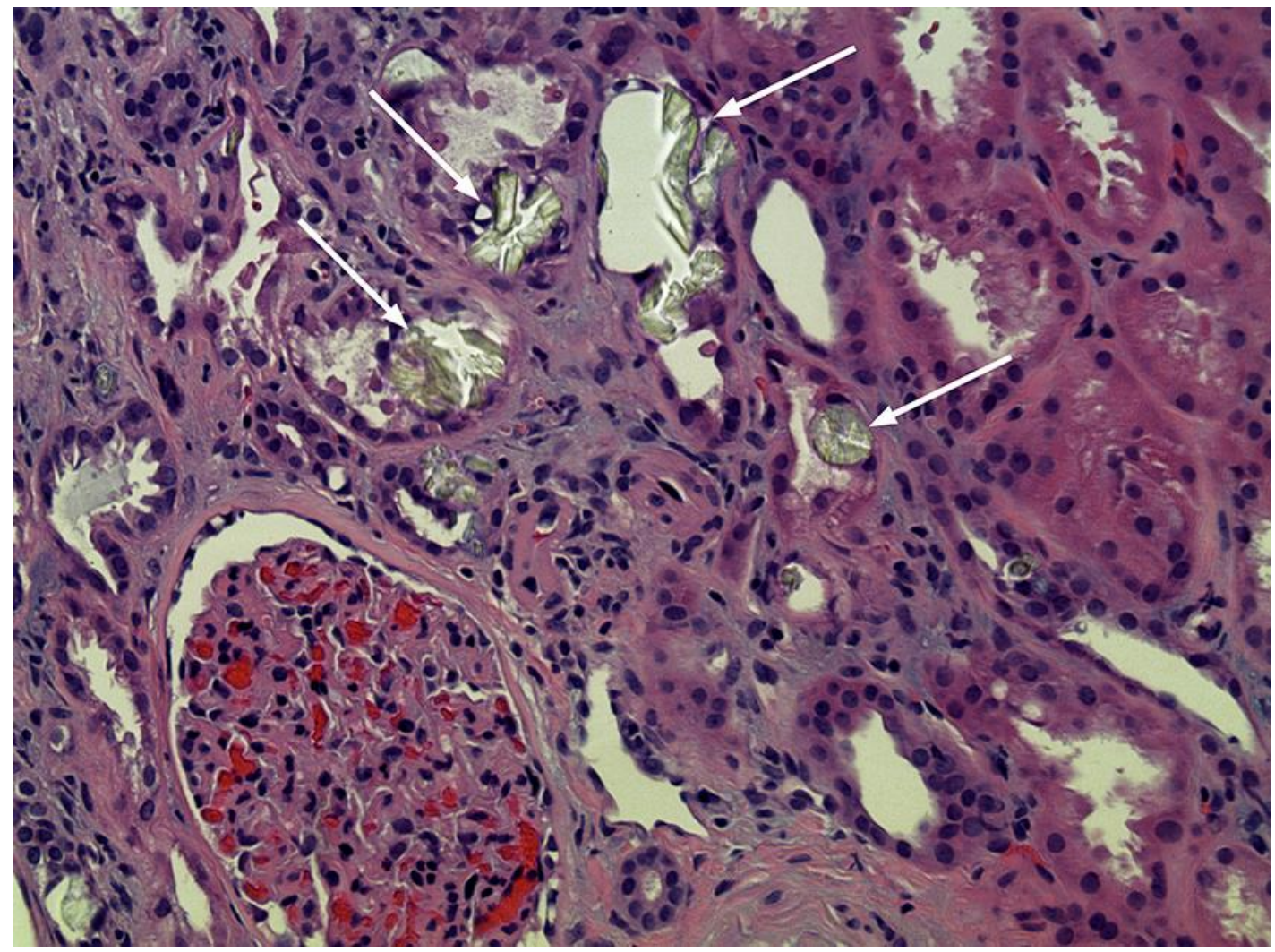

Fig. 1. Kidney biopsy specimen findings at 400× magnification with hematoxylin and eosin stain showing oxalate deposition (arrows) and tubular atrophy. 
Case Reports in Nephrology and Dialysis

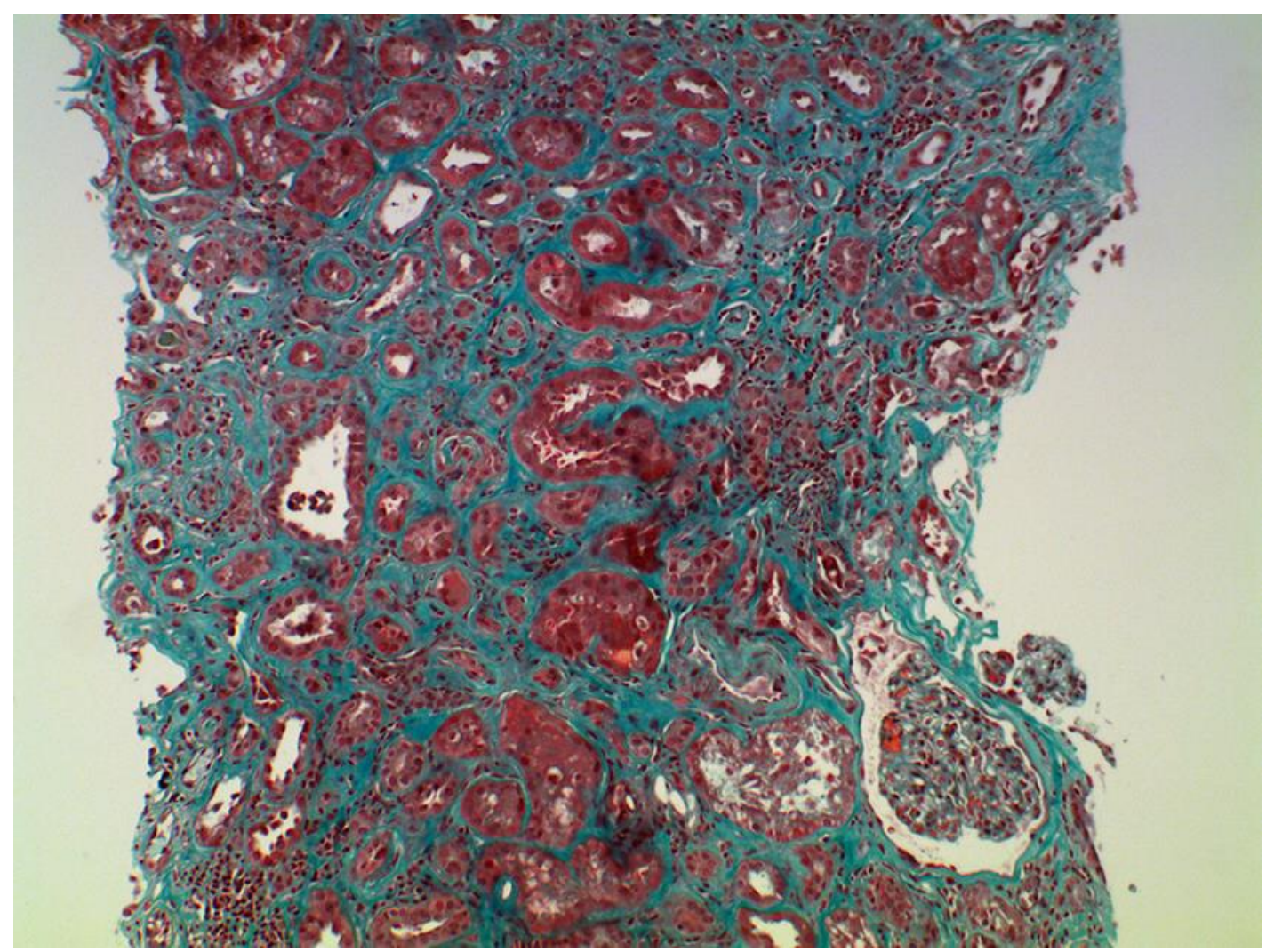

Fig. 2. Kidney biopsy specimen findings at 400× magnification with trichome stain demonstrating diffuse fibrosis. 